\title{
OTRA VUELTA DE TUERCA A LA AUTONOMÍA LOCAL Breve comentario a las SSTC 41/2016, de 3 de marzo, y 111/2016, de 9 de junio
}

\author{
ANTONIO ARROYO GIL ${ }^{1}$ \\ Profesor de Derecho constitucional \\ Universidad Autónoma de Madrid
}

\section{SUMARIO}

I. Introducción. II. La STC 41/2016, de 3 de marzo. III. La STC 111/2016, de 9 de junio. IV. Conclusiones.

\section{INTRODUCCIÓN}

Se veía venir. La Ley 27/2013, de 27 de diciembre, de Racionalización y Sostenibilidad de la Administración Local (LRSAL), que aprobó el legislador estatal al amparo de los títulos competenciales comprendidos en los subapartados 14 (hacienda general) y, sobre todo, 18 (bases del régimen jurídico de las Administraciones Públicas) del art. 149.1 CE, supuso en su momento una importante, y muy controvertida, reforma del régimen local hasta entonces vigente, articulado en torno a dos normas estatales complementarias: la Ley 7/1985, de 2 de abril, reguladora de las Bases de Régimen Local (LBRL) y el Real Decreto Legislativo 2/2004, de 5 de marzo, por el que se aprueba el texto refundido de la Ley Reguladora de las Haciendas Locales (LHL).

Más allá de las muchas críticas doctrinales de que fue objeto ${ }^{2}$, la mejor muestra de esa controversia es que numerosos artículos de la LRSAL fueron recurridos

1 Este trabajo se enmarca en el Proyecto de investigación del Programa Estatal de Fomento de la Investigación Científica y Técnica de Excelencia del Ministerio de Economía y Competitividad (DER201568160-C3-1-P) sobre «Formas de Participación política en los sistemas de gobierno multinivel y mejora de la Calidad Democrática (PACADE)».

2 Valga por todos, Medina Guerrero, Manuel: La reforma del régimen local, Tirant lo Blanch, Valencia, 2014; Font i Llobet, Tomàs/GalÁN GALÁn, Alfredo: «La reordenación de las competencias municipales: ¿una mutación constitucional?», Anuario del Gobierno Local 2013, Fundación Democracia 
por muy variados sujetos legitimados ${ }^{3}$ ante el Tribunal Constitucional, alegando diversos motivos de inconstitucionalidad.

\section{LA STC 41/2016, DE 3 DE MARZO ${ }^{4}$}

El pasado 3 de marzo de 2016, el Tribunal, con el magistrado Andrés Ollero como ponente, tuvo ocasión de pronunciarse sobre el primero de los recursos de inconstitucionalidad mencionados, el interpuesto por la Asamblea de Extremadura, que no es, por cierto, de los que cuestiona mayor número de preceptos de la LRSAL. En la STC 41/2016, de 3 de marzo (BOE, 85, de 8 de abril de 2016) se declaran, por unanimidad, inconstitucionales y nulas determinadas disposiciones

y Gobierno Local-Institut de Dret Públic, Barcelona-Madrid, 2014; buena parte de los distintos trabajos contenido en la obra colectiva coordinada por SANTAMARía PASTOR, Juan Alfonso: La reforma de 2013 del régimen local español, Fundación Democracia y Gobierno Local, Barcelona-Madrid, 2014 (en especial, vid. Velasco Caballero, Francisco: «Títulos competenciales y garantía constitucional de autonomía local en la Ley de Racionalización y Sostenibilidad de la Administración Local»); y Zafra Víctor, Manuel: Respaldo político para buenas ideas. Mi experiencia en dos direcciones generales sobre gobiernos locales, Iustel, Madrid, 2015.

3 En total, fueron 9 los recursos de inconstitucionalidad interpuestos contra la LRSAL desde 6 Comunidades autónomas (ya que en dos de ellas la ley se recurrió tanto desde la Asamblea Legislativa como desde el Gobierno: Andalucía y Cataluña), además del planteado por más de 50 diputados pertenecientes a diferentes Grupos Parlamentarios. En concreto, los recurrentes fueron: Asamblea de Extremadura; Parlamento y Consejo de Gobierno de Andalucía; Consejo de Gobierno de Asturias; Gobierno de Canarias; Gobierno y Parlamento de Cataluña; y Parlamento de Navarra. Asimismo, más de 3000 ayuntamientos de toda España, con el de Barcelona a la cabeza, promovieron un conflicto en defensa de la autonomía local.

Pese a ser parcialmente coincidentes, el Tribunal no ha acumulado ninguno de los recursos planteados, por lo que cabe esperar que en los próximos meses vaya resolviendo cada uno de ellos, aplicando la doctrina ya sentada en las dos sentencias objeto de este comentario, y ofreciendo respuesta también a aquellas cuestiones que en estos pronunciamientos no han sido resueltas, por no haber sido objeto de impugnación. Particular interés tiene, a este respecto, la solución que el TC dé al conflicto en defensa de la autonomía local.

4 A fecha de redacción de este comentario, más allá del informe de la FEMP (FEMP (Dirección General de los Servicios Jurídicos y Coordinación Territorial): «Informe relativo a la Sentencia de 3 de marzo de 2016, del Tribunal Constitucional dictada en recurso de inconstitucionalidad formulado por la Asamblea de Extremadura contra la Ley 27/2013, de 27 de diciembre, de Racionalización y Sostenibilidad de la Administración Local (LRSAL): http://femp.femp.es/files/3580-1331-fichero/Informe\%20STC\%20LRSAL\%20 Asamblea\%20Extremadura.pdf), no han sido muchos los autores que se han pronunciado por escrito sobre las SSTC 41/2016 y 111/2016. No obstante, sí es posible encontrar algunos artículos breves, o de opinión, que han sido consultados para realizar este trabajo. Son los siguientes: MERINo EstradA, V.: « $¿ Q u e ́$ fue de la reforma local?», Revista de Estudios Locales, 190, 2016; JimÉNEZ AsEnsıo, R.: «La (primera) sentencia del Tribunal Constitucional sobre la 'reforma local'», en su Blog «La mirada institucional»: https://rafaeljimenezasensio.com/2016/03/09/la-primera-sentencia-del-tribunal-constitucional-sobre-la-reforma-local/; FuERTES López, J.: «La reforma de la LBRL por la Ley 27/2013 en el Tribunal Constitucional. Sentencia del Tribunal Constitucional de 3 de marzo de 2016 (recurso interpuesto por la Asamblea de la Comunidad Autónoma de Extremadura)», Revista de Estudios Locales, 189, 2016; Borx FALOP, A.: «Comunidades autónomas y reforma del régimen local», en Agenda Pública: http://agendapublica.es/comunidades-autonomas-y-reforma-del-regimen-local/ 
de la 1 ley ${ }^{5}$, fundamentalmente por invasión de competencias autonómicas e incumplimiento de la reserva de ley orgánica del art. 157.3 CE (relativo a la financiación de las Comunidades autónomas). Queda así señalizado el camino de las sentencias que vendrán después en respuesta a las demás impugnaciones.

Pese a que no carezcan de importancia los preceptos declarados inconstitucionales, lo cierto es que en esta primera sentencia, que en buena medida se ve condicionada por otras anteriores de $2013^{6}$, el Tribunal considera que la mayoría de las disposiciones impugnadas por la Asamblea extremeña son válidas, basándose, sobre todo, en un argumento ciertamente no indiscutible: la competencia del Estado para aprobar las bases del régimen local que se deriva del hecho de que: el art. 149.1.18 CE ampara sin lugar a dudas normas básicas tendentes a introducir criterios de racionalidad económica en el modelo local español con el fin de realizar los imperativos de los arts. 32.1 y 103.1 CE y la estabilidad presupuestaria como norma de conducta a la que están sujetas las entidades locales (art. 135.2 CE)» [FJ. 3a)].

Parecería derivarse de la decisión del Tribunal Constitucional, por tanto, que posibilitar o favorecer el cumplimiento de los principios constitucionales de «eficacia» de la actuación administrativa (art. 103.1 CE) y «eficiencia» en el uso de los recursos públicos (art. 31.2 CE) es razón suficiente para dotar de legitimidad constitucional a la ley básica estatal que «introduce criterios de racionalidad económica en el modelo local español». Es decir, que el título competencial que tradicionalmente ha servido de base jurídica al Estado para establecer la legislación básica sobre régimen local, el art. 149.1.18 CE, debe ahora interpretarse a la luz de tales principios de eficiencia y eficacia administrativa, a los que se ha de sumar el de «estabilidad presupuestaria», en tanto que mandato expresamente dirigido a las entidades locales (art. 135.2 CE).

Así parece desprenderse de la afirmación de que la finalidad de la LRSAL es garantizar: la eficiencia en el uso de los recursos públicos locales y racionalizar la Administración local para asegurar su sostenibilidad y el cumplimiento de las exigencias de estabilidad presupuestaria. Conecta con el principio constitucional de estabilidad presupuestaria (art. 135 CE) y su desarrollo en la Ley Orgánica 2/2012, de 27 de abril, de estabilidad presupuestaria y sostenibilidad financiera» [FJ 2].

De hecho, en la propia Exposición de Motivos de la LRSAL se afirma que la normativa básica local y la política presupuestaria de los poderes públicos locales

5 En concreto: «el art. 57 bis de la Ley 7/1985, de 2 de abril, reguladora de las bases del régimen local (en la redacción dada por el art. 1.17 de la Ley 27/2013, de 27 de diciembre, de racionalización y sostenibilidad de la administración local) y las disposiciones adicional undécima y transitorias primera, segunda y tercera, así como los incisos «Decreto del órgano de gobierno de» y «el Órgano de Gobierno de», incluidos, respectivamente, en las disposiciones transitorias cuarta.3 y undécima, párrafo tercero, todos de la Ley 27/2013». Además, declara que la disposición adicional decimoquinta de la Ley 27/2013 no es inconstitucional siempre y cuando se interprete en los términos del fundamento jurídico 13 e) de la Sentencia.

6 SSTC 103/2013, de 25 de abril, y 143/2013, de 11 de julio, en sendos recursos de inconstitucionalidad interpuestos por el Parlamento y el Consejo de Gobierno de Cataluña en relación con determinados preceptos de la Ley 57/2003, de 16 de diciembre, de medidas para la modernización del gobierno local. 
han de adaptarse a esa nueva regulación constitucional y legal sobre estabilidad presupuestaria. Algo que, dicho sea de paso, no parecía preciso recordar con tanta insistencia, pues, de todas las Administraciones Públicas, son precisamente las Locales, en su conjunto, las que mejor se han ajustado a esas exigencias de estabilidad presupuestaria, ya que llevan cuatro años consecutivos (de 2012 a 2015) cerrando el ejercicio presupuestario con superávit.

Sea como fuere, lo que no resulta ni mucho menos pacífico es que tres normas constitucionales, dirigidas, dos de ellas, con carácter general, al conjunto del sector público, y la tercera, específicamente, a las entidades locales, puedan servir para posibilitar una determinada interpretación potenciadora de un título competencial, el estatal, y, a sensu contrario, limitadora de otros, los autonómicos. Pero lo cierto es que, según se ha señalado, ese es el argumento de fondo que emplea el Tribunal en la sentencia que ahora comentamos para avalar la constitucionalidad de la mayoría de las disposiciones impugnadas por la Asamblea de Extremadura.

Veamos seguidamente qué disposiciones declara inconstitucionales el Tribunal, y por qué motivos:

- Art. 57 bis LBRL (introducido por el art. 1.17 LRSAL), que regula el llamado sistema de compensación financiera «triangular», en virtud del cual el Estado, aunque no sea el acreedor, puede aplicar retenciones a las Comunidades autónomas en el caso de que estas no cumplan con sus obligaciones de pago frente a los entes locales. Estas retenciones se efectuarían con cargo a las transferencias que correspondan a las Comunidades autónomas por aplicación del sistema de financiación. Además, se trataría de retenciones imperativas, es decir, que se realizarían al margen de la voluntad de las partes afectadas. Pues bien, al haberse visto aquí afectada directamente una materia, las relaciones financieras del Estado con las Comunidades autónomas, que está reservada a ley orgánica, y al no haberse utilizado esta fuente del derecho para su regulación, como era preceptivo, el Tribunal considera que el art. 57 bis LBRL debe de ser declarado inconstitucional [FJ 16];

- Disposición adicional undécima LRSAL, relativa a la compensación de deudas entre Administraciones Públicas por asunción de los servicios y competencias a que se refieren las Disposiciones transitorias primera y segunda LRSAL, que, como veremos seguidamente, fueron también declaradas inconstitucionales por el Tribunal en esta sentencia. Precisamente, de la estrecha conexión de aquella adicional con estas transitorias, deriva el Tribunal la inconstitucionalidad y nulidad de la primera $[\mathrm{FJ} 13 \mathrm{c}]$;

- Disposiciones transitorias primera y segunda LRSAL, que establecen, respectivamente, la prohibición de que las Comunidades autónomas puedan atribuir a los entes locales, como «competencias propias», la 
participación en la gestión de los servicios de atención primaria a la salud, así como la prestación de los servicios sociales y de promoción y reinserción social. En estos casos, el Tribunal entiende que se produce una intromisión intolerable del Estado en el ámbito competencial autonómico, de ahí que concluya declarando la inconstitucionalidad de tales disposiciones.

En efecto, tal y como reconoce el Tribunal, los servicios sociales y de atención primaria a la salud, son: «servicios de competencia autonómica habitualmente desplegados en el nivel municipal porque así lo decidieron (o permitieron) las Comunidades Autónomas (al amparo de sus Estatutos) o el Estado (mediante la regulación ex art. 149.1.18 CE de servicios mínimos y babilitaciones directas) o, simplemente, porque fueron desarrollados de becho por los Ayuntamientos» [FJ 13a)].

En relación con los servicios sociales, la LRSAL, aparentemente, pretendió reducir las competencias propias de los municipios a la «evaluación e información de situaciones de necesidad social y la atención inmediata a personas en situación o riesgo de exclusión social», dado que la reformulación que el art. 1.8 LRSAL lleva a cabo del art. 25.2 LBRL, induce a pensar —así lo hizo al menos la Asamblea de Extremadura, siguiendo en este punto la opinión manifestada por la Abogacía del Estado en su Dictamen de 10 de diciembre de 2014- que la enumeración que en él se hace constituye numerus clausus, de lo que cabría a su vez derivar que el legislador autonómico no podría ampliar el número de materias respecto de las cuales los municipios podrían ejercer tareas. Sin embargo, no es esta la interpretación que el Tribunal ha realizado de este precepto. La sentencia considera, por el contrario, que el art. 25.2 LBRL es perfectamente constitucional, si bien debe: "excluirse la interpretación de que los municipios solo pueden obtener competencias propias en las materias enumeradas en el artículo 25.2 LBRL (...), [pues] semejante probibición, indiscriminada y general, sería manifiestamente invasiva de las competencias de las Comunidades Autónomas» [FJ 10].

En definitiva, la regulación contenida en el art. 25.2 LBRL identifica las materias respecto de las cuales los municipios deben tener, en todo caso, «competencias propias», sin que este precepto atribuya directamente tales competencias a los municipios, ya que esta es una función que corresponde necesariamente hacer a la legislación sectorial, estatal y autonómica. Además, se ha de entender que la enumeración contenida en este art. 25.2 LBRL es de mínimos, de modo que el Estado y las Comunidades autónomas, cuando consideren que existe algún interés local, podrán otorgar competencias propias a los municipios más allá de las previstas en ese precepto, y siempre y cuando, lógicamente, estas últimas lo hagan dentro del ámbito de las competencias que tienen asumidas en sus propios Estatutos de autonomía, y sin perjuicio también de que para hacerlo hayan de sujetarse a las condiciones previstas en los apartados 3, 4 y 5 del citado art. 25 LBRL (que se haga por ley, teniendo en cuenta los principios de descentralización, eficiencia, estabilidad y sostenibilidad financiera; que se incluya una memo- 
ria económica que refleje el impacto sobre los recursos financieros de las Administración Públicas afectadas y el cumplimiento de los principios de estabilidad, sostenibilidad financiera y eficiencia del servicio o actividad, y que se prevea la dotación de los recursos necesarios para asegurar la suficiencia financiera de las Entidades Locales sin que ello pueda conllevar, en ningún caso, un mayor gasto de las Administraciones públicas; y que se garantice que no se produce una atribución simultánea de la misma competencia a otra Administración pública).

Así las cosas, nada tiene de extraño que, como hemos visto, el Tribunal declarara inconstitucionales las referidas Disposiciones transitorias primera y segunda LRSAL. El argumento de fondo es claro: el Estado «sólo podrá atribuir competencias locales específicas, o probibir que estas se desarrollen en el nivel local, cuando tenga la competencia en la materia o sector de que se trate».

Por su parte, «tên materias de competencia autonómica, sólo las Comunidades Autónomas pueden atribuir competencias locales o probibir que el nivel local las desarrolle».

En consecuencia, el legislador básico estatal se ha extralimitado en este punto del título competencial derivado del art. 149.118. CE [FFJJ 10 y 13 c)]:

- Disposición transitoria tercera LRSAL, que dispone la asunción por las Comunidades autónomas de los servicios de inspección sanitaria que venían prestando los municipios. Entiende aquí el Tribunal que se han extralimitado los márgenes de la competencia básica del art. 149.1.18 CE, produciéndose, en consecuencia, una invasión de las competencias autonómicas estatutariamente asumidas (al prohibirles la descentralización de tales servicios a favor de los municipios de su correspondiente ámbito territorial) [FJ $13 \mathrm{~d}$ )];

- Disposición transitoria cuarta.3 LRSAL, en concreto, aquel inciso que determina el tipo de norma y el órgano autonómico competente («Decreto del órgano de gobierno») para acordar la disolución de las entidades locales menores ya constituidas en el supuesto de que no presenten sus cuentas ante los organismos correspondientes del Estado y de la Comunidad autónoma. Entiende el Tribunal que en este caso el Estado excede claramente los límites de su competencia, al tratarse de una cuestión de organización administrativa que incumbe determinar en exclusiva a la propia Comunidad Autónoma [FJ 7];

- Disposición transitoria 11. ${ }^{a}$, párrafo tercero, LRSAL, en concreto, aquel inciso que determina el órgano autonómico competente («Órgano de Gobierno de la Comunidad Autónoma») para declarar la disolución de las mancomunidades que no hayan adaptado sus Estatutos a la LRSAL. El Tribunal reproduce aquí el razonamiento utilizado en relación con la supresión de las entidades locales menores: Al tratarse de una cuestión propia de la autonomía organizativa de las Comunidades autónomas, no le corresponde al legislador estatal básico determinar cuál es el órgano au- 
tonómico competente para llevar a cabo tal declaración de disolución de las mancomunidades [FJ 8].

Al margen de la declaración de inconstitucionalidad de estos preceptos, el Tribunal se pronuncia también sobre otras cuestiones que merecen alguna atención. Aunque no es posible detenernos aquí en todas ellas, sí conviene fijarse un momento en las siguientes, con marcado acento crítico:

Así, en el caso de la Disposición adicional decimoquinta LRSAL se prevé el traspaso a las Comunidades autónomas de determinadas competencias educati$\operatorname{vas}^{7}$. A fin de salvar la constitucionalidad de esta disposición, el Tribunal realiza un esfuerzo de interpretación sistemática conforme. Tras entender que la LRSAL incurre en una «evidente antinomia», al imponer a las Comunidades autónomas «obligaciones de signo opuesto» imposibles de cumplir simultáneamente — descentralizar (art. 25.2.n) LBRL) y centralizar tales servicios educativos (Disposición adicional decimoquinta LRSAL) — el Tribunal concluye, a fin de resolver tal contradicción, que, en realidad, la norma de la LRSAL no impone a las Comunidades autónomas una obligación de centralizar esas competencias: "cabe interpretar que el legislador básico no ba probibido que la ley autonómica atribuya aquellas tareas como competencia propia municipal. Consecuentemente, las Comunidades Autónomas no están obligadas a centralizarlas; antes bien, están obligadas a asegurar que los municipios dispongan "en todo caso» de competencias propias dentro de ellas (art. 25.2 n) LBRL)» [FJ 13e)].

Según el Tribunal, esta es la interpretación correcta de la Disposición adicional decimoquinta LRSAL, que, a fin de evitar posibles confusiones, se lleva al Fallo.

Desde una perspectiva más general, en esta sentencia el Tribunal entronca con una arraigada jurisprudencia constitucional sobre el régimen local que considera que el mismo no es «intracomunitario» ni «extracomunitario», sino «bifronte», en consonancia con la estructura territorial de España (art. $137 \mathrm{CE}$ ), que concibe a municipios y provincias como elementos de división y organización del territorio del Estado. Esto es, el Estado y las Comunidades Autónomas comparten la regulación del régimen local, sin perjuicio del espacio que uno y otras deben asegurar en todo caso a las normas locales en virtud de la garantía constitucional de la autonomía municipal (art. 140 CE), provincial (art. 141.2 CE) e insular (art. $141.4 \mathrm{CE})^{8}$.

La regulación del régimen local, según esta línea jurisprudencial, correspondería, en sus aspectos básicos, al Estado, como consecuencia del título competen-

7 «[P]articipar en la vigilancia del cumplimiento de la escolaridad obligatoria y cooperar con las Administraciones educativas correspondientes en la obtención de los solares necesarios para la construcción de nuevos centros docentes, así como la conservación, mantenimiento y vigilancia de los edificios de titularidad local destinados a centros públicos de educación infantil, de educación primaria o de educación especial» (Disposición adicional decimoquinta LRSAL).

8 STC 82/1982, de 21 de diciembre, FFJJ 3.a) y 4. 
cial reconocido a su favor en el art. 149.1.18 CE («bases del régimen jurídico de las Administraciones Públicas»). Así pues, el Estado, a través de su normativa básica, concreta el alcance de la autonomía local constitucionalmente reconocida, $\mathrm{y}$, en consecuencia, define los aspectos esenciales del régimen local, en un sentido más o menos amplio o restrictivo, según sus preferencias, ya que el único límite que debe, en todo caso, respetar es el de dejar espacio suficiente, por un lado, a las Comunidades autónomas para que aprueben su propia normativa de desarrollo, y, por el otro, a las propias Entidades Locales para que a través de sus respectivos órganos puedan participar en los asuntos de gobierno y administración que directamente les incumben.

Esta jurisprudencia, sin perjuicio de que haya sido cada vez más cuestionada por parte de la doctrina, por considerar que no pone suficientemente el acento en el carácter democrático de los gobiernos locales, lo que impediría considerarlos meramente como un «objeto material» a disposición de la normativa estatal y autonómica, ha venido aplicándose, de manera constante, matices al margen, hasta la actualidad. Sin embargo, es preciso reconocer que a partir de la reforma del art 135 CE, en septiembre de 2011, el entendimiento de uno de los elementos centrales de la misma, el relativo al título competencial del Estado previsto en el art. 149.1.18 CE, se ha visto alterado de manera sustancial, en la medida en que a partir de ese momento se ha considerado que, como señalamos más arriba, tal título competencial ofrece también cobertura a la aprobación de normas básicas que constriñan el régimen local al cumplimiento de los principios de «eficiencia» en el uso de los recursos públicos (art. 31.2 CE), «eficacia» de la actuación administrativa (art. 103.1 CE) y «estabilidad presupuestaria» (art. 135.1 CE).

La vis expansiva que puede despegar un título competencial del Estado así entendido es incuestionable. No obstante, el Estado debería tener presente al hacer uso de él que su competencia básica para establecer cuáles son los criterios de racionalidad económico-presupuestaria a respetar tanto por las Comunidades autónomas como por los Gobiernos locales, ha de convivir con el principio de autonomía de aquellas y estos, también reconocido en la propia Constitución con carácter estructural. Es más, en mi opinión, ofrecería serias dudas de constitucionalidad una aplicación excesivamente generosa de aquella competencia del Estado que supusiese una alteración de la posición constitucional que ocupan tanto las Comunidades autónomas como los Gobiernos locales. Esto es algo que debería tener muy presente el propio Estado a la hora de legislar, por supuesto, pero también el Tribunal Constitucional.

Por lo que se refiere al mapa municipal, el Tribunal salva la constitucionalidad del art. 1.5 LRSAL (que modifica el art. 13 LBRL) amparándose en el argumento central antes expuesto: Aunque la competencia sobre alteración de los términos municipales corresponde a las Comunidades autónomas (art. 148.1.2 CE y normas respectivas de los Estatutos de Autonomía), el Estado, a partir de lo previsto en el art. 149.1.18 CE, sí es competente para «diseñar el modelo municipal español» y establecer las bases del procedimiento de alteración de los términos municipales, 
pudiendo disponer, por ejemplo, «mayores exigencias de población y territorio» para la creación de nuevos municipios. De igual modo, también es competente para establecer medidas destinadas a facilitar o fomentar las fusiones voluntarias, mediante la consignación de subvenciones, por ejemplo, «con el fin de lograr una reducción del mapa municipal», cumpliendo de este modo con los susodichos principios de eficacia de la actuación administrativa (art. 103.1 CE), eficiencia en el uso de los recursos públicos (art. 31.2 CE) y estabilidad presupuestaria (art. 135 CE) ${ }^{9}$.

«La exigencia de que se creen nuevos municipios solo cuando resulten financieramente sostenibles (...), si no deriva directamente de los arts. 31.2, 103.1 y 135 CE, entra dentro, sin lugar a dudas, de la competencia estatal para diseñar el modelo municipal español; exactamente igual la fijación de mínimos poblacionales: el Estado puede desarrollar un modelo municipal al amparo del art. 149.1.18 CE «basado en mayores exigencias de población y territorio», si lo considera «necesario para garantizar la viabilidad del ejercicio de las competencias que se atribuyen a los municipios y con ello su autonomía» (STC 103/2013, FJ 5)»[FJ 6].

Por lo que se refiere a las Entidades Locales no necesarias (entidades locales menores y mancomunidades, principalmente), dado su «fuerte grado de interiorización autonómica», y al no verse vinculadas directamente a la garantía constitucional de la autonomía local (arts. 140 y $141 \mathrm{CE})^{10}$, corresponde en exclusiva a las Comunidades autónomas su creación o disolución, a través del instrumento normativo y del órgano autonómico correspondientes, sin que a este respecto el Estado pueda intervenir. Lo que sí podrá hacer este, apoyándose en los principios de eficacia, eficiencia y estabilidad presupuestaria, es establecer ciertos límites a la creación de aquellas [FJ 5].

\section{LA STC 111/2016, DE 9 DE JUNIO ${ }^{11}$}

Cuando apenas habían transcurrido tres meses escasos desde la STC 41/2016, el Tribunal Constitucional resolvió un nuevo recurso de inconstitucionalidad contra la LRSAL, formulado, en esta ocasión, por el Consejo de Gobierno de Andalucía, a través de la STC 111/2016, de 9 de junio de 2016, con el Magistrado Antonio Narvaez como ponente.

9 Que el Estado podía establecer válidamente incentivos a la fusión municipal era algo sobre lo que ya el Tribunal se había pronunciado con anterioridad de manera clara y afirmativa (SSTC 214/1989, de 21 de diciembre; y 103/2013, de 25 de abril)

10 STC 214/1989, FFJJ 4 b) y 15 a).

11 Vid. el breve comentario a esta setencia realizado por Almonacid Lamelas, V.: «TC versus LRSAL: segundo asalto», en Blog Administración Pública en legaltoday.com (04.07.2016): http://www.legaltoday.com/blogs/transversal/blog-administracion-publica/emtc-versus-lrsal-segundo-asaltoem 
En ella, además de declarar extinguida, por pérdida sobrevenida de objeto, la impugnación de determinados preceptos de la LRSAL cuya inconstitucionalidad había sido ya declarada en la sentencia de 3 de marzo (en concreto, el art. 57 bis LBRL, en la redacción dada por el art. 1.17 LRSAL, y las Disposiciones adicional undécima y transitorias primera, segunda y tercera, así como el inciso «Decreto del órgano de gobierno de» incluido en la Disposición transitoria cuarta.3 LRSAL), en esta nueva resolución el Tribunal declara inconstitucionales y nulas las siguientes disposiciones:

Los incisos del art. 26.2 LBRL (en la redacción dada por el art. 1.9 LRSAL): «al Ministerio de Hacienda y Administraciones Públicas» y «para reducir los costes efectivos de los servicios el mencionado Ministerio decidirá sobre la propuesta formulada que deberá contar con el informe preceptivo de la Comunidad Autónoma si es la Administración que ejerce la tutela financiera». El Tribunal entiende que del art. 149.1.18 CE no cabe derivar a favor del Estado funciones de carácter ejecutivo, tal y como ha venido sosteniendo el propio Tribunal en jurisprudencia reiterada ${ }^{12}$, de ahí que haya que considerar una invasión de la competencia autonómica la atribución de una función de tal carácter a favor del Ministerio de Hacienda y Administraciones Públicas en el referido art. 26.2 LBRL.

Respecto de las materias a las que se refiere la mayor parte de los servicios enumerados en este artículo son las Comunidades autónomas las que tienen conferidas las competencias ejecutivas: «gestión en materia de protección del medio ambiente» (art. 148.1.9 CE), «sanidad e higiene» (art. 148.1.21 CE), proyección, construcción y explotación de los «aprovechamientos hidráulicos» y «aguas minerales y termales» (art. 148.1.10 CE), «ordenación del territorio, urbanismo y vivienda» (art. 148.1.3 CE), «ferrocarriles y carreteras cuyo itinerario se desarrolle íntegramente por el territorio de la Comunidad Autónoma» (art. 148.1.5 CE) y «obras públicas de interés de la Comunidad Autónoma en su propio territorio» (art. 148.1.4 CE).

Por su parte, aunque el art. 149.1.23 CE reconoce al Estado competencia en materia de medio ambiente, esta alcanza solo a las bases, sin que, por tanto, este precepto pueda dar cobertura a tareas de ejecución como la ahora enjuiciada ${ }^{13}$. Otro tanto cabe afirmar respecto de los títulos coordinación general y bases de la sanidad interior (art. 149.1.16 CE ${ }^{14}$. Por todo ello, los incisos arriba mencionados son declarados inconstitucionales y nulos.

Disposición adicional $16 .^{a}$ LBRL, introducida por el art. 1.38 LRSAL, con los efectos ex nunc señalados en el FJ 8 f), de modo que a partir de la publicación de esta sentencia (15 de julio de 2016), «cuando el Pleno de la Corporación no alcanzara, en una primera votación, la mayoría necesaria para la adopción de

12 SSTC 214/1989, FJ 1; y 41/2016, FFJJ 3 a), 5, 6 c) y 7 c).

13 Por todas, STC 33/2005, de 17 de febrero, FFJJ 8 y 9.

14 SSTC 32/1983, de 28 de abril, FJ 2; 42/1983; de 20 de mayo FJ 3. 
acuerdos», ya no podrá aprobarse por parte de la Junta de Gobierno Local: «el presupuesto del ejercicio inmediato siguiente, siempre que previamente exista un presupuesto prorrogado»; «los planes económico-financieros, los planes de reequilibrio y los planes de ajuste a los que se refiere la Ley Orgánica 2/2012, de 27 de abril»; «los planes de saneamiento de la Corporación Local o los planes de reducción de deudas»; y «[l]a entrada de la Corporación Local en los mecanismo extraordinarios de financiación vigentes a los que se refiere la Ley Orgánica 2/2012, de 27 de abril, y, en particular, el acceso a las medidas extraordinarias de apoyo a la liquidez previstas en el Real Decreto-ley 8/2013, de 28 de junio, de medidas urgentes contra la morosidad de las administraciones públicas y de apoyo a Entidades Locales con problemas financieros».

La razón de fondo que lleva al Tribunal a declarar la inconstitucionalidad de esta Disposición adicional 16. ${ }^{\mathrm{a}} \mathrm{LBRL}$ entronca directamente con un determinado entendimiento del principio democrático. Para el Tribunal, la referida disposición, "al burtar al pleno — como órgano constitucionalmente necesario de los ayuntamientos y diputaciones - de tareas sumamente trascendentes, (...), y al atribuirlas a la junta de gobierno —como órgano eventual, carente de relieve constitucional y configurado legalmente con marcado "carácter ejecutivo»_ (...) ba impuesto un sacrificio a un principio medular, definitorio de la propia autonomía local (arts. 137, 140 y 141 CE) y de la competencia estatal misma que da cobertura a la intervención legislativa (art. 149.1.18 CE); un principio constitucionalmente proclamado como valor superior del ordenamiento jurídico (art. 1.1 CE; STC 204/2011, de 15 de diciembre, FJ 8). No se trata de negar la legitimidad democrática o la capacidad representativa con que también cuenta, naturalmente, la junta de gobierno local. Se trata de constatar que la disposición adicional decimosexta LBRL afecta singularmente a dos dimensiones del principio democrático, convenientemente aisladas por la STC 42/2014, de 25 de marzo, FJ 4 a): de un lado, la dimensión que exige tendencialmente que las decisiones vinculadas al destino de la comunidad sean tomadas conforme al principio mayoritario por órganos colegiados de naturaleza representativa; $y$, de otro, la que garantiza, también tendencialmente, que, en el marco de procedimientos deliberativos, la minoría pueda formular propuestas y expresar su opinión sobre las propuestas de la mayoría, sin predeterminar necesariamente resultados, pero con la posibilidad abstracta de influir en ellos» [FJ $8 \mathrm{c}$ )].

Afirmado este «inequívoco» sacrificio del principio democrático, el Tribunal se pregunta, acto seguido, si existe alguna razón que lo justifique. En concreto, sostiene que «no puede perderse de vista que este principio, en cuanto tal, no puede cerrar los amplísimos espacios de configuración que la Constitución asigna al legislador básico a la bora de regular los órganos de gobierno locales y repartir tareas entre ellos; en lo que abora importa, obliga solo a que, respecto de aquellas decisiones determinantes de la vida de la comunidad local (...), tenga muy buenas razones para sustraerlas a la competencia del órgano representativo que expresa el pluralismo político de esa comunidad así como para suprimir o reducir los beneficios inberentes a la democracia deliberativa. Ello exige desarrollar un juicio — calificado de "ponderación» en la doctrina constitucional- que identifique los bienes en juego, calibre su importancia y determine si el beneficio asegurado a uno 
compensa el sacrificio impuesto a otro ( "regla de prevalencia condicionada», en términos de la STC 103/2001, de 23 de abril, FJ 10)» [FJ 8 c)].

Y en esa tarea de identificación del otro término de la ponderación, el Tribunal no duda en señalar que el mismo no es otro que el «principio constitucional de estabilidad presupuestaria (art. $135 \mathrm{CE}$ )».

Nos encontramos, por consiguiente, ante dos principios que tienen expreso reconocimiento constitucional (principio democrático: art. 1.1 CE / principio de estabilidad presupuestaria: art. $135 \mathrm{CE}$ ), y que, según el Tribunal, ostentan, "prima facie, la misma relevancia constitucional. Sin embargo, es más que evidente que no son equivalentes, esto es, bienes a los que la Constitución haya asignado el mismo peso. Ya se ha explicado suficientemente que la democracia es principio fundacional del propio Estado constitucional (STC 259/2015, de 2 de diciembre, FJ 5), «valor superior de nuestro ordenamiento reflejado en el art. 1.1 CE» (STC 204/2011, FJ 8) y fundamento, tanto de la autonomía local (STC 103/2013, FJ 6), como de la competencia estatal misma para regular los órganos de gobierno de los entes locales y para repartir asuntos entre ellos (STC 33/1993, FJ 3) [FJ 8 d)].

Pues bien, a partir de estas consideraciones generales, y de otras más específicas sobre la concreta aplicación de la disposición cuestionada, así como sobre la existencia de mecanismos que permiten superar las situaciones de bloqueo en la adopción de decisiones por parte de los órganos municipales, el Tribunal llega a la conclusión de que «las ventajas (eventuales e indirectas) para la estabilidad presupuestaria propiciadas en algunos casos por la disposición adicional decimosexta LBRL no superan ampliamente — ni compensan minimamente — los relevantes perjuicios causados al principio democrático. (...) En lo que abora importa, la disposición aquí controvertida establece una solución que vulnera el principio democrático al imponer sobre él un sacrificio muy relevante que no puede entenderse justificado en otros valores, bienes o principios» [FJ 8 d)].

Con la declaración de inconstitucionalidad, y consiguiente nulidad, de este precepto, con efectos ex nunc, el Tribunal ha abierto una vía interpretativa que podría permitir embridar en el futuro la desorbitada vis expansiva que, tanto a nivel normativo como jurisprudencial, ha tenido un principio como el de estabilidad presupuestaria desde el momento de su «consagración» constitucional en septiembre de 2011. Habrá que estar atentos a la evolución que experimente su aplicación e interpretación. Sea como fuere, hay que celebrar, en este punto, el sentido de la sentencia, en la medida en que el Tribunal ha puesto ya un límite muy claro a ese principio de estabilidad presupuestaria que parecía destinado a «arrasar» con algunos de los fundamentos político-territoriales de nuestro Estado.

En relación con esta misma Disposición adicional 16. ${ }^{a}$ LBRL, en su Voto particular, el Magistrado Ricardo Enríquez, si bien comparte el criterio de la mayoría acerca de la vulneración por este precepto del principio democrático, excluye, sin embargo, de tal consideración lo relativo a los planes económico-financieros y de reequilibrio, ya que — en su opinión — con la traslación a la Junta de Gobierno de la aprobación de los mismos se puede evitar la adopción de ulte- 
riores medidas «más intrusivas en el principio de autonomía local «, como son las «coercitivas y de cumplimiento forzoso», que, en el peor de los casos, tal y como está previsto en la Ley Orgánica de Estabilidad Presupuestaria y Sostenibilidad Financiera, podrían llegar hasta la disolución de los órganos de la Corporación Local incumplidora. Medidas estas que se pueden imponer a aquellas Administraciones Públicas que incumplan el objetivo de estabilidad presupuestaria, deuda pública o la regla de gasto y que no hayan aplicado medidas correctivas como la presentación de los referidos planes económico-financieros o de reequilibrio.

El inciso «El Consejo de Gobierno de» incluido en el segundo párrafo, in fine, del art. 97 del texto refundido de las disposiciones legales vigentes en materia de régimen local, aprobado por Real Decreto Legislativo 781/1986, de 18 de abril, en la redacción dada por la Disposición final primera de la LRSAL. La razón de la declaración de inconstitucionalidad de este inciso no es otra que la esgrimida en los FF.JJ. 7 c) y 8 b) de la STC 41/2016 anteriormente comentada: La vulneración de la potestad autonómica de autoorganización.

Además de estas declaraciones de inconstitucionalidad, el Tribunal resuelve que los arts. 36.1 g) y 36.2 a), segundo párrafo, LBRL, en la redacción dada por el art. 1.13 LRSAL, no son inconstitucionales siempre y cuando sean interpretados tal y como se dispone en los FFJJ 11 y 12 c), respectivamente, de esta Sentencia. Quiere esto decir, en relación con el primero de estos preceptos, que a las diputaciones provinciales, consejos y cabildos insulares, así como a las Comunidades autónomas uniprovinciales les seguirá correspondiendo «[1]a prestación de los servicios de administración electrónica y la contratación centralizada en los municipios con población inferior a 20.000 habitantes».

El Tribunal entiende que el art. $36.1 \mathrm{~g}$ ) LBRL no transfiere a la diputación provincial, en su totalidad, la prestación de servicios de administración electrónica y de la contratación en municipios con menos de 20.000 habitantes, pues algo así sería incompatible con la potestad de autoorganización que corresponde a los propios municipios, incluidos los de menor población, como manifestación de la autonomía que tienen constitucionalmente garantizada en el art. $137 \mathrm{CE}$. Antes bien, en ejercicio de una interpretación sistemática, hay que entender que el art. $36.1 \mathrm{~g}$ ) LBRL se limita a incluir atribuciones nuevas que especifican la más general de «asistencia y cooperación jurídica, económica y técnica a los municipios, especialmente los de menor capacidad económica y de gestión», prevista en la letra b) de este art. 36.1 LBRL.

A mayor abundamiento, hay que tener también presente que el art. 31.2a) LBRL establece como «fines propios y específicos de la Provincia garantizar los principios de solidaridad y equilibrio intermunicipales, en el marco de la política económica y social y, en particular: (...) Asegurar la prestación integral y adecuada en la totalidad del territorio provincial de los servicios de competencia municipal». De esta forma, se ha de entender que lo que pretende el art. $36.1 \mathrm{~g}$ ) LBRL es hacer efectivos unos servicios, en el ámbito de la administración electrónica y de la contratación, que los municipios con población inferior a 20.000 habitantes 
pueden no ser capaces de satisfacer adecuadamente. Cumple así la diputación provincial la función institucional que le es más propia: cooperar y prestar asistencia a los municipios de su ámbito territorial en el desempeño de las tareas que los mismos tienen encomendadas. De ahí que, según el Tribunal, no pueda entenderse que se produce una vulneración de la autonomía municipal. Por el contrario, esta actividad provincial contribuye a que la misma sea real y efectiva.

Por otro lado, en relación con el art. 36.2 LBRL, se ha de tener presente que el legislador estatal, a partir de su título competencial comprendido en el art. 149.1.18 CE, y según lo ha venido entendiendo la jurisprudencia constitucional, puede o bien incrementar o bien reducir las competencias de las diputaciones provinciales (la autonomía constitucionalmente garantizada: arts. 137 y $141 \mathrm{CE}$ ), siempre y cuando ello no implique una vulneración del principio de autonomía municipal, que goza también de la correspondiente garantía constitucional (arts. 137 y $140 \mathrm{CE}$ ). Es más, en la medida en que la provincia viene determinada por la agrupación de municipios, cuyos órganos de gobierno (los Ayuntamientos) son elegidos directamente por los vecinos, cabe entender que a estos les corresponde un grado de autonomía superior al que cabe reconocer a las diputaciones provinciales. $\mathrm{O}$, dicho de otro modo, la autonomía provincial, en todo caso, puede servir al fin de hacer real y efectiva la autonomía municipal, cuando esta se vea en riesgo a causa de la escasa capacidad de gestión de los municipios como consecuencia de sus dimensiones. Lo que no sería de recibo es que esa misma autonomía provincial viniese a debilitar la autonomía de los municipios de su ámbito territorial.

A partir de esta premisa de fondo, según reconoce el propio Tribunal Constitucional, "(l)a garantía constitucional de la autonomía local no impide por sí que el legislador atribuya a la diputación provincial competencias de coordinación en sentido estricto, como "límite efectivo" al ejercicio de las atribuciones municipales (STC 214/1989, FJ 18). Los arts. 137 y 140 CE no imposibilitan esta atribución, imponen solo condiciones. (...) la competencia provincial de coordinación, además de estar especificamente atribuida y suficientemente determinada, debe responder a la protección de intereses supramunicipales; una amplia indeterminación normativa equivale a confiar a la propia entidad coordinadora la forma y alcance de su "cierto poder de dirección" sobre el ente coordinado; un poder que estaría, en realidad, autoatribuido en contra de la doctrina constitucional. A su vez, el legislador, dentro de los amplios márgenes con que cuenta para diseñar fórmulas de coordinación provincial, debe asegurar que el grado de capacidad decisoria que conserve el municipio sea tendencialmente correlativo al nivel de interés municipal presente en el asunto de que se trate. Tal como recuerda la STC 154/2015, de 9 de julio, FJ 6 a), "se trata de que el legislador gradúe el alcance o intensidad de la intervención local 'en función de la relación existente entre los intereses locales y supralocales dentro de tales asuntos o materias' (SSTC 32/1981, FJ 4; 170/1989, 19 de octubre, FJ 9, y 51/2004, FJ 9, entre muchas; en el mismo sentido, últimamente, SSTC 95/2014, de 12 de junio, FJ 5; 57/2015, de 18 de marzo, FJ 6, y 92/2015, de 14 de mayo, FJ 4)”" [FJ 12 c)]. 
Esta es la doctrina constitucional que hay que aplicar en la interpretación del art. 36.2 LBRL para salvaguardar su constitucionalidad. De este modo, la fórmula de coordinación que establezca la diputación a sus municipios cuando la prestación de determinados servicios por parte de estos tenga un coste superior al que tendría si los mismos servicios se prestasen por la propia diputación, o bajo la coordinación de ella, solo será válida si se permite que los municipios participen con carácter previo en la elaboración y aprobación de los planes provinciales de actuación. En palabras del Tribunal: «La previsión impugnada debe interpretarse, por tanto, en el sentido de que precisa de complementos normativos que, en todo caso, deben dejar márgenes de participación a los municipios» [FJ 12 c)].

\section{CONCLUSIONES}

A la espera de que se vayan resolviendo los recursos de inconstitucionalidad aún pendientes y, sobre todo, el conflicto en defensa de la autonomía local, podemos afirmar ya sin miedo a equivocarnos que la que se pretendía gran reforma del régimen local de finales de 2013 ha quedado completamente «desactivada» en sus aspectos fundamentales, relativos, sobre todo, al orden competencial, por tres motivos: su propio alcance (mucho más limitado de lo que en un principio se anunció); el ulterior desarrollo normativo llevado a cabo por numerosas Comunidades autónomas, contrario, en buena medida, a la filosofía de fondo en que se inspiraba la reforma, y que fue aceptado por la propia Administración General del Estado a partir de marzo de 2015, mediante acuerdos transaccionales suscritos con las Comunidades autónomas, y, en lo relativo a los servicios sociales, a través de una Carta del Secretario de Estado de Administraciones Públicas y de una Nota Explicatorio de la Reforma Local que, de manera un tanto vergonzante, con cesión a las presiones autonómicas, asumía que tales servicios seguirían prestándose por los Ayuntamientos a partir del 31 de diciembre, fecha de finalización del período transitorio establecido en la Disposición Transitoria segunda LRSAL, hasta que se aprobaran las normas reguladoras del sistema de financiación autonómica y local; y las sentencias del Tribunal Constitucional vistas, la primera de las cuales, como hemos destacado, declara inconstitucional la referida Transitoria segunda, así como la primera y la tercera.

Desde el punto de vista de la autonomía local constitucionalmente garantizada, en términos generales, estas sentencias apuntan en la buena dirección, si bien tampoco significan, como ha sido celebrado, quizás, con algún exceso de optimismo, un claro reforzamiento de aquella. En realidad, el Tribunal Constitucional, en buena medida, se ha dedicado a dar continuidad a su ya vieja jurisprudencia sobre régimen local, dando señales, en este sentido, poco esperanzadoras sobre una previsible evolución de la misma que tienda verdaderamente a reforzar la dimensión política de aquella en el complejo entramado institucional del Estado autonómico. 
Seguramente, estas limitaciones de la jurisprudencia constitucional no sean fácilmente superables. Al fin y al cabo, no es un Tribunal el órgano más adecuado para configurar los contornos de un nivel de gobierno, el local, en este caso, que, como tal, demanda de un soporte normativo de alto rango que ofrezca seguridad jurídica suficiente. De hecho, lo «ideal» sería que, por fin, se acometiese una reforma de la Constitución que, entre otras cosas, regulase con mayor densidad normativa los elementos institucionales y competenciales básicos de los gobiernos locales, ya que ese sería el mejor modo de preservar y hacer efectiva su capacidad de autogobierno, frente a posibles intervenciones posteriores del Estado o de las Comunidades autónomas que pretendieran ponerla en riesgo. Sin embargo, hasta que llegue ese momento, si es que algún día llega, la labor que puede desempeñar el Tribunal Constitucional tampoco se puede despreciar, en la medida en que el mismo puede extraer del texto constitucional vigente, vía hermenéutica, ciertos contenidos mínimos del régimen local que cualquier legislador posterior, ya sea estatal o autonómico, debe respetar. Las sentencias aquí analizadas, en alguna medida, apuntan en esa dirección. Cabe esperar que las que están por llegar sigan por esa misma senda. Si así fuese, será una señal inequívoca, sobre todo, para el futuro legislador básico estatal, que habría de acometer la regulación de los elementos esenciales del régimen local con más respeto de lo que lo ha hecho el de 2013. Y es que no parece que sea conveniente seguir dando vueltas de tuerca a la autonomía local, ya que el riesgo de que la misma acabe en exceso retorcida o, peor aún, deformada, es muy elevado.

$$
\text { *** }
$$

TITLE: Brief commentary on the SSTC 41/2016 and 111/2016

ABSTRACT: The Constitutional Court begins to solve the unconstitutionality actions brought against the Rationalization and Sustainability of Local Administration Law. Its analized in this paper the content of the first two sentences (SSTC 41/2016, and 111/2016), which mostly reiterate well-established case law.

RESUMEN: El Tribunal Constitucional comienza a resolver los recursos de inconstitucionalidad interpuestos contra la Ley 27/2013, de 27 de diciembre, de Racionalización y Sostenibilidad de la Administración Local (LRSAL). Analizamos aquí con sentido crítico el contenido de las dos primeras sentencias recaídas (SSTC 41/2016, de 3 de marzo, y 111/2016, de 9 de junio), que en su mayor parte vienen a reiterar jurisprudencia ya consolidada, si bien no se ha de despreciar alguna orientación que parece más «sensible» hacia la autonomía local constitucionalmente garantizada.

KEY WORDS: local autonomy; Local reform; municipalities; local map; Rationalization Law and Sustainability of the Local Administration; Constitutional Court ruling.

Palabras Clave: Autonomía local; reforma local; municipios; diputaciones; mapa local; Ley de Racionalización y Sostenibilidad de la Administración Local; sentencia del Tribunal Constitucional.

FECHA DE RECEPCIÓN: 20.06.2016

FECHA DE ACEPTACIÓN: 27.07.2016 